\title{
Simultaneous Bilateral Endoscopic Surgery (SBES) for Bilateral Urolithiasis: the Future? Evidence from a Systematic Review
}

\author{
Robert M. Geraghty ${ }^{1} \cdot$ Patrick Jones $^{1} \cdot$ Bhaskar K. Somani ${ }^{1,2}$ \\ Published online: 21 February 2019 \\ (C) The Author(s) 2019
}

\begin{abstract}
Purpose of Review Urolithiasis is a disease of prevalence across the world and up to a quarter of patients present with multiple stones. Most procedures carried out in this scenario are staged; however, there is a growing body of evidence to suggest bilateral simultaneous (BS) procedures are safe. We performed a systematic review to investigate and evaluate the evidence for these procedures.

Recent Findings A systematic review was conducted according to Cochrane and PRISMA checklist for all English-language articles from January 1996 to January 2018 using Medline, CINAHL, Scopus, EMBASE, Cochrane library, Clinicaltrials.gov and Google Scholar. All studies (a minimum of 10 patients) with bilateral simultaneous percutaneous nephrolithotomy (BSPCNL) or bilateral simultaneous ureteroscopy (BS-URS) and ipsilateral URS with contralateral simultaneous PCNL were included. Data was extracted for patient and stone demographics, outcomes and stone-free rate (SFR) and the level of evidence (using the GRADE assessment tool). Overall, 32 studies (1966 patients) were included in the review after the identification of 302 articles in the search. This included 16 studies (1073 patients) with BS-URS, 13 studies (750 patients) with BS-PCNL and 3 studies (143 patients) with URS and simultaneous contralateral PCNL. Of these, 8 were comparative studies and compared bilateral simultaneous procedure to either a unilateral or staged comparator. The mean operating time, SFR, the Clavien I-II and the Clavien $\geq$ III were $75 \mathrm{~min}, 91 \%, 22 \%$ and $1.4 \%$ for BS-URS; $157 \mathrm{~min}, 92 \%, 27 \%$ and $6.4 \%$ for BS-PCNL; $151 \mathrm{~min}, 76 \%$ and $5.6 \%$ for URS with contralateral PCNL. In comparison to staged procedures, although the SFR and complication rates were similar, there was a significantly reduced operative time and hospital stay with simultaneous procedures $(p<0.001)$.

Summary Although evidence for bilateral simultaneous endourological procedures is limited, results from available studies show that outcomes are at least equivalent to staged procedures. Key advantages seem to be reduced operative times, cost and hospital stay which will lead to an increased uptake of these procedures in the future.
\end{abstract}

Keywords Ureteroscopy $\cdot$ URS $\cdot$ PCNL $\cdot$ Bilateral $\cdot$ Simultaneous $\cdot$ Endourology $\cdot$ RIRS $\cdot$ Retrograde intrarenal surgery

$\begin{array}{ll}\text { Abbreviations } & \\ \text { SWL } & \text { Shockwave lithotripsy } \\ \text { URS } & \text { Ureteroscopy } \\ \text { PCNL } & \text { Percutaneous nephrolithotomy } \\ \text { BS-URS } & \text { Bilateral simultaneous ureteroscopy } \\ \text { BS-PCNL } & \text { Bilateral simultaneous PCNL } \\ \text { SFR } & \text { Stone-free rate } \\ \text { PRISMA } & \text { Preferred Reporting Items for Systematic } \\ & \text { Reviews and Meta-analyses }\end{array}$

This article is part of the Topical Collection on Endourology

Bhaskar K. Somani

b.k.somani@soton.ac.uk; bhaskarsomani@yahoo.com

1 Department of Urology, University Hospital Southampton NHS Trust, Southampton SO16 6YD, UK

2 University of Southampton, Southampton, UK

\section{Introduction}

Urolithiasis is a disease of prevalence across the world. Up to $25 \%$ have multiple stones at the time of presentation $[1 \bullet \bullet$, $2-4]$ and a third of asymptomatic stones eventually require intervention [2]. The potential advantages to be gained by treating multiple or bilateral stones in a single operation such as single anaesthetic, reduced hospital stay and cost savings appeal to both surgeon and patient. Choice of treatment is determined by patient demographics, stone size and location [2]. The three main interventions for stone treatment are shockwave lithotripsy (SWL), ureteroscopy (URS) and percutaneous nephrolithotomy (PCNL) [2, 3]. A recent review has shown that URS is gradually becoming an increasingly popular treatment modality across the world, while practice patterns for SWL have been in decline [3]. 
The evolution of minimally invasive endourology techniques has led to the rise in simultaneous bilateral procedures. Technological advancements in optics, digitalisation and laser fragmentation techniques have all played a part in this process. Miniaturisation of equipment has also been a central part of this. While bilateral simultaneous endourological procedures have gained increased attention, a comprehensive review is required that incorporates all bilateral simultaneous endourological procedures or provides a clear comparison of bilateral simultaneous ureteroscopy (BS-URS), bilateral simultaneous PCNL (BS-PCNL) or combined bilateral procedures with staged endourological procedures. To this end, we performed a systematic review to evaluate the feasibility, safety and efficacy of bilateral simultaneous endourological procedures.

\section{Methods and Materials}

\section{Evidence Acquisition: Criteria for Considering Studies for This Review}

$\mathrm{P}$ - Adults with bilateral urolithiasis

I - Bilateral simultaneous procedures (BS-URS, BS-PCNL and simultaneous URS with contralateral PCNL)

$\mathrm{C}$ - Staged or unilateral endourological procedures

$\mathrm{O}$ - Stone-free rate (SFR), complication rate, hospital stay, operative time

$\mathrm{S}$ - Systematic review

The inclusion criteria are as follows:

1) English-language articles

2) Patients of any age

3) All articles reporting on bilateral simultaneous URS or PCNL or URS with contralateral PCNL, for urolithiasis

The exclusion criteria include:

1) Older studies using the same data as a more recent study where the longest follow-up was included

2) Studies examining treatment for non-urolithiasis conditions

3) Studies with less than 10 patients

\section{Search Strategy and Study Selection}

The systematic review was performed according to the Cochrane style and in accordance with the Preferred Reporting Items for Systematic Reviews and Meta-analyses (PRISMA) checklist [5]. The search strategy was conducted to find relevant studies from Ovid Medline without revisions (January 1996-January 2018), Cochrane Library (2018), CINAHL (January 1996-January 2018), EMBASE (January 1996-January 2018), Scopus (January 1996-January 2018),
Clinicaltrials.gov, Google Scholar and individual urologic journals.

The search terms used included 'ureteroscopy', 'URS', 'ureterorenoscopy', 'retrograde intra-renal surgery', 'RIRS', 'percutaneous nephrolithotomy', 'PCNL', 'PNL', 'bilateral', 'simultaneous', 'synchronous', 'single-session', 'same-session', 'calculi*', 'stone*', 'nephrolithiasis' and 'urolithiasis'. Boolean operators (AND, OR) were used to refine the search.

The search was limited to English-language articles between January 1996 and January 2018. Authors of the included studies were contacted in the case of data not being available or unclear. If the authors did not reply, data was estimated from the graphs and other data provided in the study. If the data could not be estimated, then the study was excluded from analysis. A cutoff of 10 patients was set to include centres with the minimum relevant endourological experience. All original studies were included and where more than one articles were related to the same study, the longest follow-up was included.

Two experienced reviewers (RG and BS) identified all studies. All studies that appeared to fit the inclusion criteria were included for full review. Each reviewer independently selected studies for inclusion in the review [see Fig. 1]. Any discrepancy was resolved by mutual consensus.

\section{Data Extraction and Analysis}

The following variables were extracted from each study: year of publication, study type, SFR and definition of SFR, sample size, treatment modality, age, stone size, stone size, stent insertion for URS, type of URS, tubeless or standard PCNL, number of PCNL access tracts, complications, hospital stay, operative time, follow-up time and imaging modality. Data was collated using Microsoft Excel (version 12.2.4). Quality of evidence was assessed and bias was analysed using the GRADE assessment tool [6].

\section{Results}

Overall, 32 studies (1966 patients) were included in the review after the identification of 302 articles in the search. This included 16 studies (1073 patients) with BS-URS, 13 studies (750 patients) with BS-PCNL and 3 studies (143 patients) with URS and simultaneous contralateral PCNL. Of these, 8 were comparative studies and compared bilateral simultaneous procedure to either a unilateral or staged comparator.

\section{Bilateral Simultaneous Ureteroscopy (Table 1)}

There were 16 studies [7-11] of bilateral simultaneous ureteroscopy (BS-URS), including 1073 patients (660 men, 413 women) with a mean age of 46.5 years. Stone proportions were reported in size or burden by different studies and are 
Fig. 1 Inclusion criteria for studies analysed

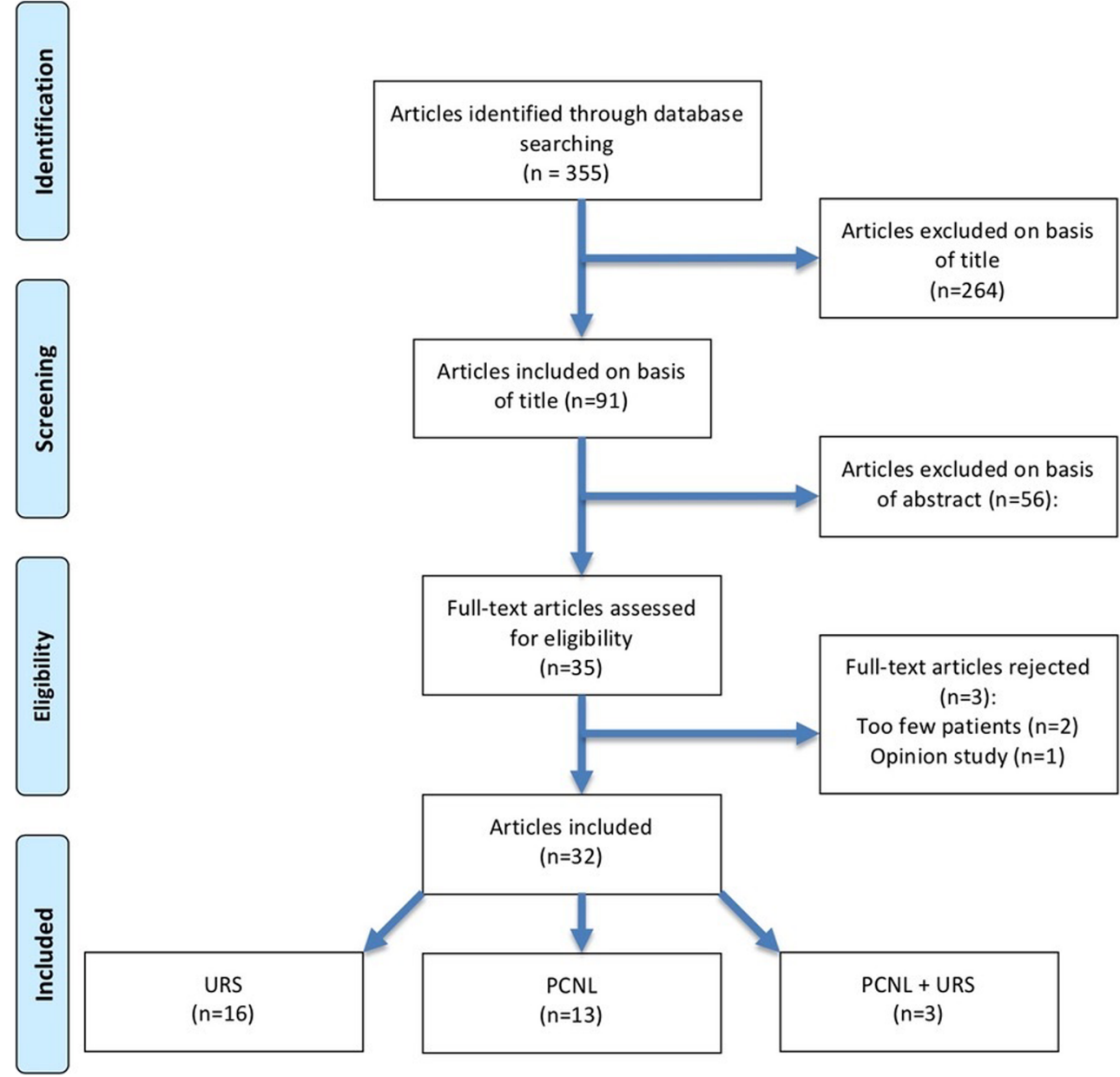

summarised in Table 1. The mean operative time was $75.4 \mathrm{~min}$. Post-operative stent insertion rates varied between 65 and $100 \%$.

Follow-up imaging was variable with only one study using a CT scan exclusively and the majority of other studies using a combination of USS and plain XR KUB. The overall SFR was $90.5 \%$, with a minor complication (the Clavien I-II) rate of $22.4 \%$ and a major complication (the Clavien $\geq$ III) rate of $1.4 \%$. The mean hospital stay across the studies was 1.6 days. While the Clavien I-II complications included fever $(n=34)$, haematuria $(n=52)$, infection $(n=11)$, pain/stent symptoms $(n=55)$ and mucosal injury $(n=40)$, the Clavien III-V complications included ureteral perforation $(n=9)$, acute kidney injury (AKI) $(n=1)$, sepsis $(n=3)$ and death $(n=2)$.

\section{Bilateral Simultaneous PCNL (Table 2)}

There were 13 studies of bilateral simultaneous percutaneous nephrolithotomy (BS-PCNL) [12-14], including 750 patients with a mean age of 47.1 years. Stone proportions were reported in size or burden by different studies and are summarised in Table 2. The mean operative time was $156.9 \mathrm{~min}$. Nephrostomy insertion and use of multiple access tracts are detailed in Table 2. Except for one study [13] which presented data of multiple tracts in all 27 patients, the use of multiple access tracts varied from 7 to $24 \%$ and was used in 7 studies.

Follow-up imaging and timings were variable with 5 studies using a CT scan and others using a combination of USS and plain XR KUB. The overall SFR was $92.0 \%$, with a complication rate of $33 \%$. Of these, minor complications were seen in 202 patients $(27 \%)$ with major complications seen in 48 patients $(6.4 \%)$. The mean hospital stay across the studies was 4.9 days.

While the minor complications included fever $(n=23)$, transfusion $(n=31)$, infection $(n=11)$ and renal fistula $(n=$ $10)$, the major complications included AKI $(n=1)$, hydrothorax $(n=11)$, delayed stenting $(n=6)$, urine leak $(n=7)$ and sepsis $(n=1)$. However, it was not specified in a total of 122 minor complications and 19 major complications.

\section{Ureteroscopy with Simultaneous Contralateral PCNL (Table 3)}

There were 3 studies [15-17] of URS with simultaneous contralateral PCNL including 143 patients with a mean age of 53.1 years. Stone proportions were reported in size or burden 


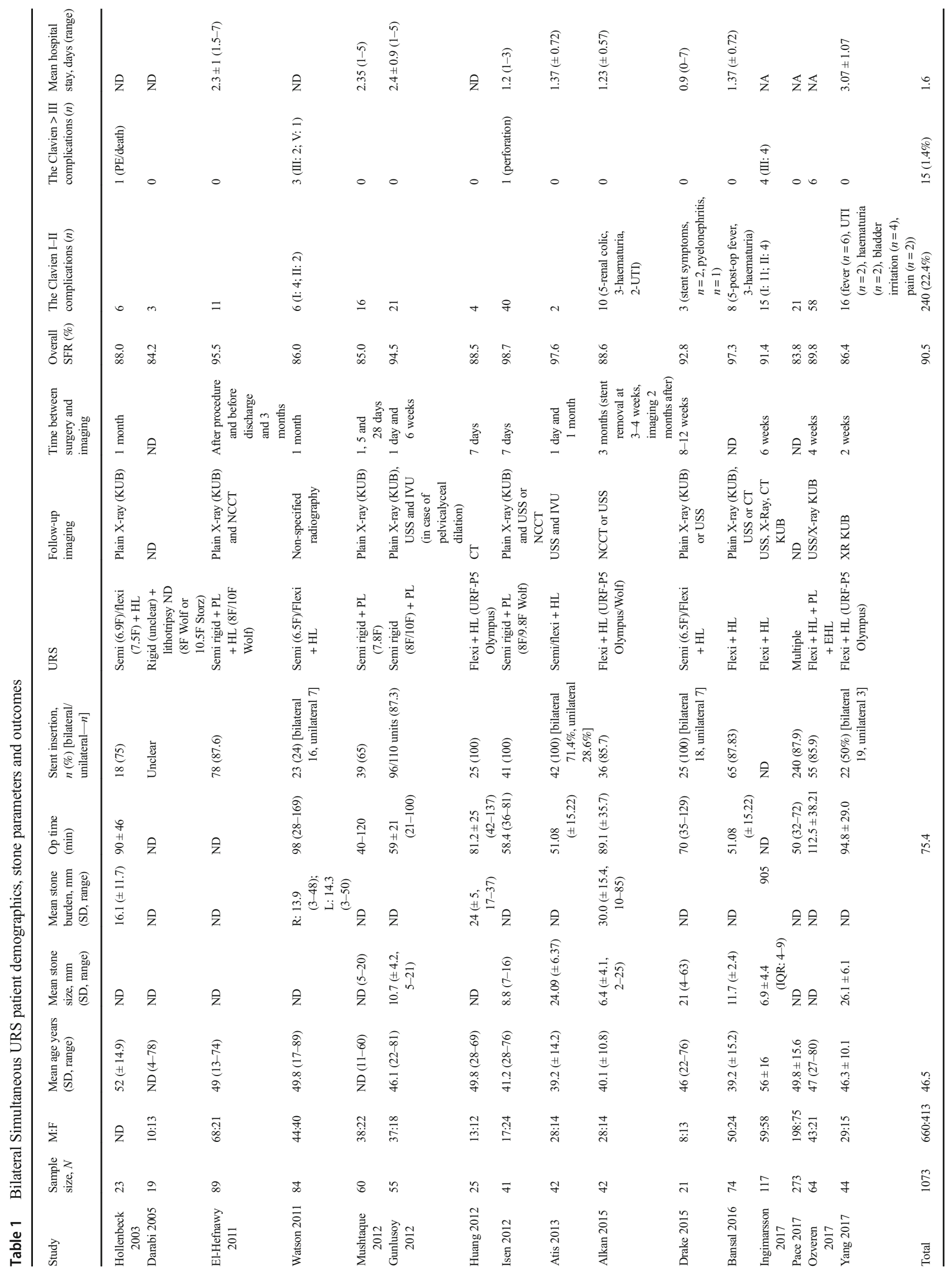




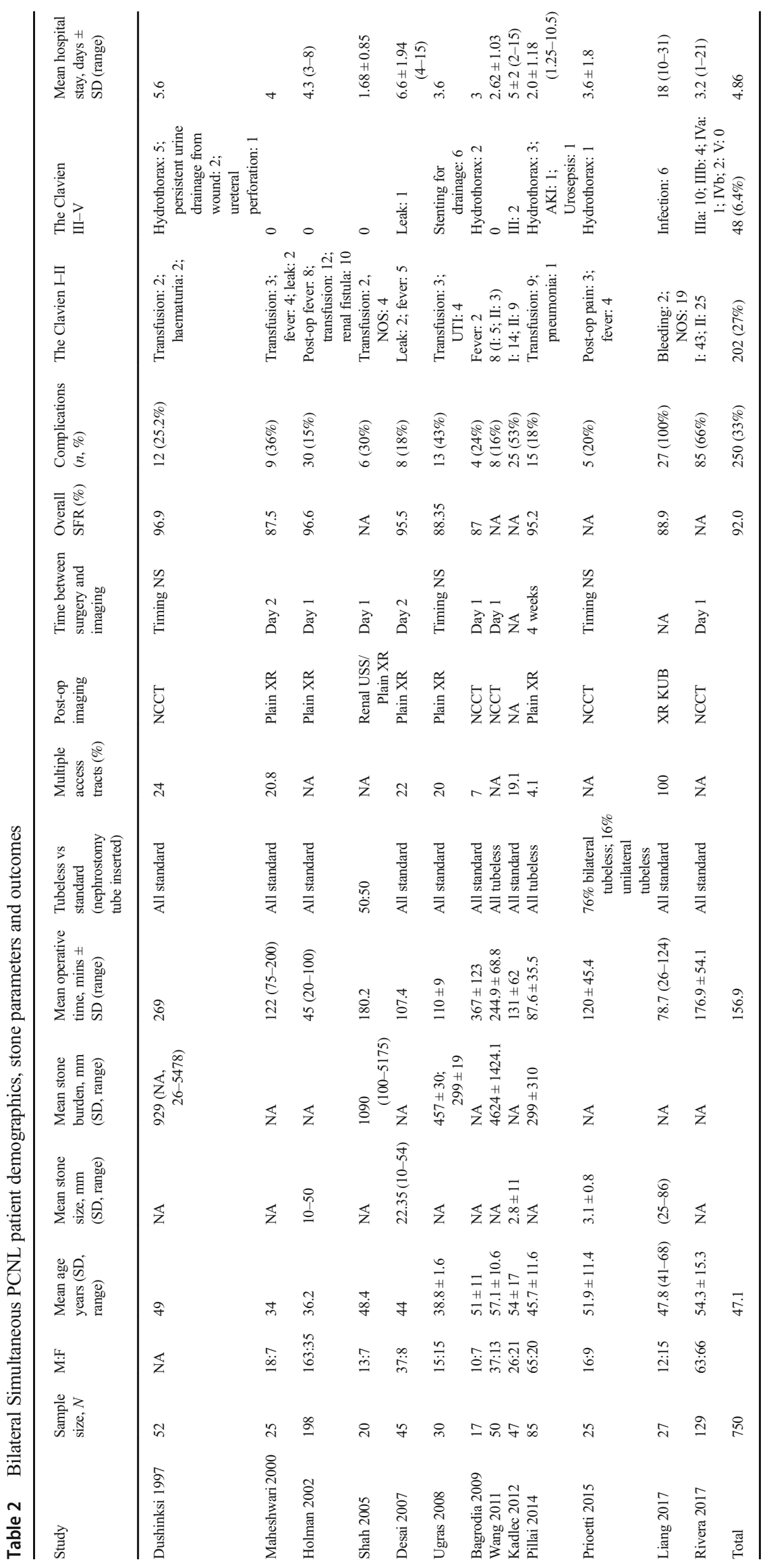




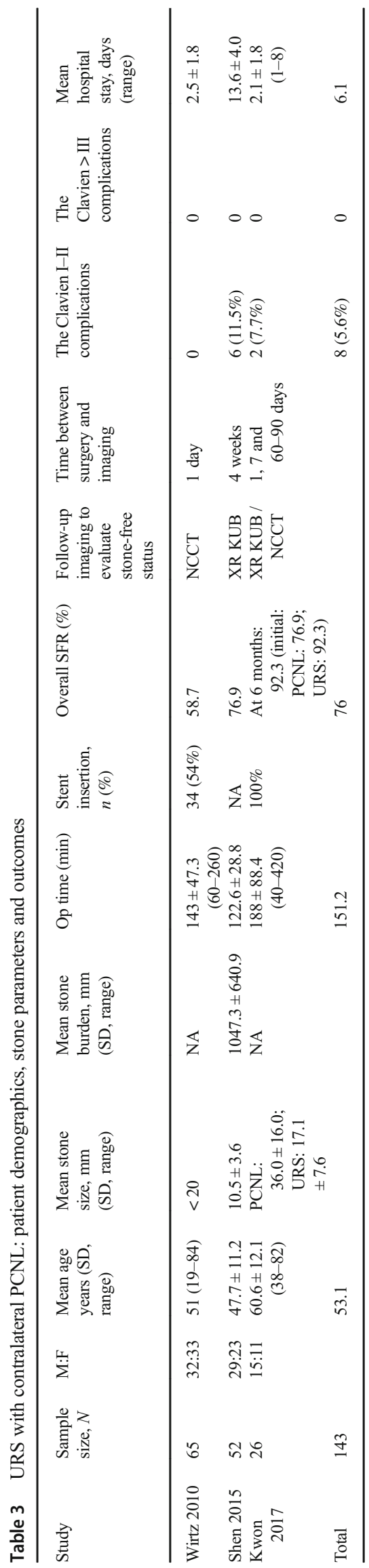

by different studies and are summarised in Table 3 . The mean operative time over the three studies was $151.2 \mathrm{~min}$ and an overall SFR of $76 \%$ was recorded.

Follow-up imaging and timing have been detailed in Table 3. The minor complication (the Clavien I-II) rate was $5.6 \%$ and there were no major complications. The mean hospital stay was 6.1 days.

\section{Comparative Studies (Tables 4 and 5)}

Of the 32 studies included in this review, there were only 8 comparative studies. They compared the bilateral simultaneous endourological procedures to either a unilateral or staged comparator (Tables 4 and 5).

There were 4 comparative studies examining BS-URS; 3 of those compared BS-URS to unilateral URS and one study compared BS-URS to both unilateral and staged URS procedures. There were no significant differences in any of the studies between BS-URS and the comparator treatments for operation time, SFR, hospital stay or complications (Tables 4 and 5).

There were 3 comparative studies examining BS-PCNL. Wang et al. [18] compared BS-PCNL versus staged PCNL procedures whereas the remaining 2 studies compared it to unilateral PCNL procedures $[14,19]$. Wang et al. demonstrated that there was no difference between BS-PCNL and staged procedures for SFR and complications, with significantly shorter operative time and hospital stay [18]. Similarly, the complication rates for BS-PCNL was significantly higher than compared to the unilateral comparator PCNL procedure (34$53 \%$ in BS-PCNL compared to $27-31 \%$ in unilateral PCNL comparator group, $p<0.001$ ) [14, 19] (Table 5).

There was only one study comparing URS with simultaneous contralateral PCNL $(n=52)$ compared to a staged procedure $(n=51)$ [16] (Table 5). There was no significant difference between the two for SFR or complication rate. However, there was significantly reduced operative time and hospital stay for bilateral combined procedures.

\section{Bias Analysis (Fig. 2)}

The overall quality of evidence was graded as 'very low' and risk of bias as detailed in Fig. 2 was mostly 'at serious' risk. Of the 32 studies, only 8 were comparative and of those only 2 of those were controlled studies (Table 6). There were also 2 case-control studies and 3 prospective cohorts; the remainder were retrospective cohorts (Table 6).

There were large differences in how 'stone-free' status was defined. The definitions were as follows: no stones $(n=6),<$ $1 \mathrm{~mm}(n=2),<2 \mathrm{~mm}(n=4),<3 \mathrm{~mm}(n=1),<4 \mathrm{~mm}(n=8)$, $<5 \mathrm{~mm}(n=1)$. Ten studies did not provide any definition on how 'stone-free' status was determined. 


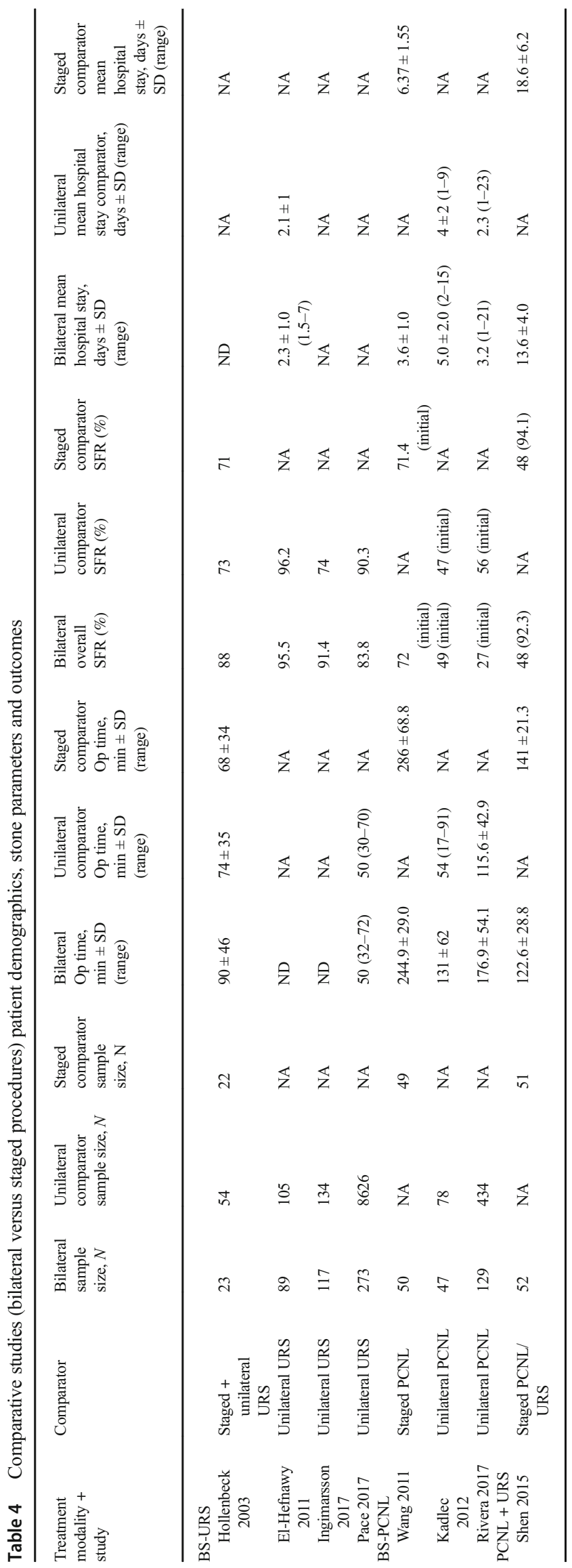




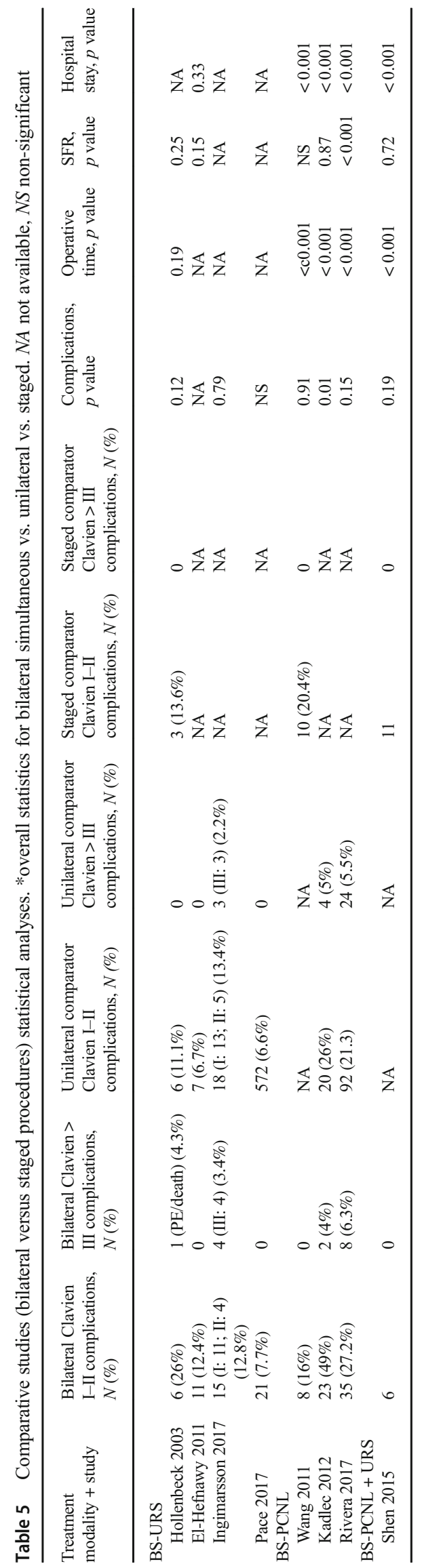

\section{Discussion}

\section{Meaning of the Study}

This review provides an up to date and comprehensive overview on bilateral simultaneous endourological procedures for bilateral stone disease [7-21]. A total of 1966 patients (across 32 studies) were included. The overall SFRs for BS-PCNL and BS-URS were in excess of $90 \%$ reflecting the efficacy of this technique. Although the overall complications were higher for patients that underwent BS-PCNL, this is likely to reflect patients with larger and potentially more complex stones (Table 7). Although most complications across the studies were minor in nature, a lot of these were fully detailed.

\section{Comparison of Bilateral Simultaneous Procedures to Staged or Unilateral Procedures}

There were 8 comparative studies and of those studies comparing bilateral simultaneous procedures to staged or unilateral procedures, it was obvious that the complications were higher when the procedures were done simultaneously $[16$, $18,21]$. However, when these figures were calculated on the basis of a number of renal units rather than the number of patients, the frequency of complications in bilateral procedures was less than for staged procedures [12]. This provides a strong argument for carrying out bilateral simultaneous endourological procedures rather than the additional morbidity with staged procedures.

Case volume would also have a part to play and centres with higher volumes were shown to have lower complications with a higher SFR $[7,12,22]$. Clearly, the cost argument would be in favour of doing these procedures simultaneously with an overall reduction in operative time and hospital stay associated with the combined approach. The cost of consumables would also decrease as the same set-up and ancillary equipment could be used for the procedures on the contralateral side [12].

\section{Recommendations for Clinical Practice Based on Our Study}

Although our study shows the feasibility and outcomes of bilateral simultaneous endourological procedures, most studies included were from specialist endourological centres reflecting a high case volume and surgical expertise. The outcomes need standardisation and cost and quality of life need to be considered [23, 24]. Careful patient selection and optimisation is paramount and not all patients will be suitable for this option. If the procedure on the first side is performed as planned, only then should the contralateral side be attempted. Careful pre-operative counselling is also very important. 


\begin{tabular}{|c|c|c|c|c|c|c|c|}
\hline \multicolumn{7}{|c|}{ Certainty assessment } & \multirow[t]{2}{*}{ Certainty } \\
\hline $\begin{array}{l}\text { No of } \\
\text { studies }\end{array}$ & Study design & Risk of bias & Inconsistency & Indirectness & Imprecision & Other considerations & \\
\hline \multicolumn{8}{|c|}{ Bilateral Simultaneous Ureteroscopy } \\
\hline 14 & $\begin{array}{l}\text { Observational } \\
\text { studies }\end{array}$ & $\begin{array}{l}\text { Very } \\
\text { serious }\end{array}$ & Not serious & Serious & Serious & $\begin{array}{l}\text { Very strong association } \\
\text { All plausible residual confounding would } \\
\text { reduce the demonstrated effect }\end{array}$ & Very Low \\
\hline \multicolumn{8}{|c|}{ Bilateral Simultaneous Percutaneous Nephrolithotomy } \\
\hline 12 & $\begin{array}{l}\text { Observational } \\
\text { studies }\end{array}$ & $\begin{array}{l}\text { Very } \\
\text { serious }\end{array}$ & Not serious & Serious & Serious & $\begin{array}{l}\text { Very strong association } \\
\text { All plausible residual confounding would } \\
\text { reduce the demonstrated effect }\end{array}$ & Very Low \\
\hline \multicolumn{8}{|c|}{ Percutaneous Nephrolithotomy with Contralateral Ureteroscopy } \\
\hline 3 & $\begin{array}{l}\text { Observational } \\
\text { studies }\end{array}$ & Serious & Not serious & Serious & Serious & $\begin{array}{l}\text { Very Strong association } \\
\text { All plausible residual confounding would } \\
\text { reduce the demonstrated effect }\end{array}$ & Very Low \\
\hline
\end{tabular}

Fig. 2 Bias analysis

As part of this, the patients should therefore be made aware that it may only be feasible to clear the stones on a single side that day with the contralateral procedure deferred for another day.

\section{Strengths, Limitations and Implications for Future Research}

The main strength of this study is the adherence of the methodological approach to Cochrane guidelines and the PRISMA checklist [5]. A risk of bias analyses was also performed to allow the data to be placed into context [6]. However, as with any systematic review, the study is limited by the available literature, which is mostly retrospective cohort studies. There were only two controlled trials, one of which was randomised $[7,12,18]$. As there were not enough comparative studies for a meta-analysis, this was not performed. The heterogeneity of results reported by the individual studies was such that only a pooled analysis was possible. Nor was a comparison made between the different treatment modalities as there are different indications for URS and PCNL [2], which meant that they could not be directly compared.

There is a lack of epidemiological studies on bilateral kidney or ureteric stones. The last study to be performed was in 1981 by Ahlstrand and Tiselius [4]. They studied 138,585 inhabitants of a Swedish town covering all ages. There were 191 renal colic patients, of which 2 had bilateral stones. A more recent paediatric study by Coward et al. [20] studied 121 children $(<17$ years) over a 5 -year period with acute admissions for stone disease. Twenty-two (18.2\%) of those patients had bilateral stones (14/53 metabolic aetiology and $8 / 68$ non-metabolic aetiology). These studies suggest that the proportion of patients with bilateral urolithiasis is low and therefore, urologists may not encounter it regularly. However, with the rise in kidney stone disease (KSD), this is likely to change and therefore, this choice of treatment approach may well be adopted more in the future.

Bilateral simultaneous procedures are not performed routinely. Rivera et al. reported on a survey of 153 endourologists [14]. Of those who responded, 38\% performed BS-PCNL, $48 \%$ performed BS-URS but not BS-PCNL and $14 \%$ performed no bilateral simultaneous procedures at all. The reasons cited for not performing bilateral simultaneous procedures included the risks involved with the operative duration, potential for bilateral renal injury and risk of bleeding. However, majority (131/153) of endourologists would be happy to perform BS-URS for bilateral stone burdens. This reflects the awareness and potential anxiety amongst urologists about the complication rate of BSPCNL. However, this study has shown that the complication profile associated with BS-PCNL is similar to BSURS, although statistical equivalence has not been proven.

Future studies should include large-scale randomised controlled trials, which compare bilateral simultaneous procedures versus staged procedures, ensuring that there is homogeneity between trials. The selection criteria and outcome measures need to be standardised. Data can then be combined formally in a meta-analysis to provide the highest quality of evidence. Similarly, epidemiological studies should be undertaken to examine the risks and true extent of bilateral stone disease across all patient groups $[25,26]$. Developing a universally agreed definition of SFR would also help meaningful comparisons to be made [23]. With expanding indications of ureteroscopy to include large stones, pregnancy and paediatric patients, the indications and uptake of bilateral simultaneous procedures are likely to rise in the future $[26,27]$. 
Table 6 Type of studies, level of evidence (LOE) and stone-free rate (SFR) definition

\begin{tabular}{|c|c|c|c|}
\hline Study & Type & LOE & SFR definition \\
\hline \multicolumn{4}{|c|}{ BS-URS study demographics } \\
\hline Hollenbeck 2003 & Retrospective & 4 & ND \\
\hline Darabi 2005 & Retrospective & 4 & $\mathrm{ND}$ \\
\hline El-Hefnawy 2011 & Retrospective & 4 & $\mathrm{ND}$ \\
\hline Mushtaque 2012 & Retrospective & 4 & Unclear \\
\hline Gunlusoy 2012 & Retrospective & 4 & No stones \\
\hline Huang 2012 & Retrospective & 4 & $<1 \mathrm{~mm}$ \\
\hline Isen 2012 & Retrospective & 4 & $<4 \mathrm{~mm}$ \\
\hline Atis 2013 & Retrospective & 4 & $<4 \mathrm{~mm}$ \\
\hline Alkan 2015 & Retrospective & 4 & $<4 \mathrm{~mm}$ \\
\hline Drake 2015 & Retrospective & 4 & $<2 \mathrm{~mm}$ \\
\hline Bansal 2016 & Retrospective & 4 & $<4 \mathrm{~mm}$ \\
\hline Ingimarsson 2017 & Case control & 3 & No stones \\
\hline Pace 2017 & Prospective cohort & 3 & $<1 \mathrm{~mm}$ \\
\hline Ozveren 2017 & Retrospective & 4 & $<2 \mathrm{~mm}$ \\
\hline \multicolumn{4}{|c|}{ BS-PCNL study demographics } \\
\hline Dushinksi 1997 & Retrospective cohort & 4 & $<4 \mathrm{~mm}$ \\
\hline Maheshwari 2000 & Retrospective cohort & 4 & NA \\
\hline Holman 2002 & Retrospective cohort & 4 & $<4 \mathrm{~mm}$ \\
\hline Shah 2005 & Retrospective cohort & 4 & $<5 \mathrm{~mm}$ \\
\hline Desai 2007 & Retrospective cohort & 4 & $<3 \mathrm{~mm}$ \\
\hline Ugras 2008 & Prospective cohort & 3 & NA \\
\hline Bagrodia 2009 & Retrospective cohort & 4 & NA \\
\hline Wang 2011 & $\mathrm{RCT}$ & 2 & NA \\
\hline Kadlec 2012 & Case control & 3 & $<4 \mathrm{~mm}$ \\
\hline Pillai 2014 & Retrospective cohort & 4 & NA \\
\hline Prioetti 2015 & Retrospective cohort & 4 & NA \\
\hline Liang 2017 & Retrospective cohort & 4 & No stones \\
\hline \multicolumn{4}{|c|}{ PCNL + URS study demographics } \\
\hline Wirtz 2010 & Retrospective cohort & 4 & No stones \\
\hline Shen 2015 & Controlled trial & 3 & No stones \\
\hline Kwon 2017 & Retrospective cohort & 4 & $\begin{array}{c}\text { Absence of } \\
\text { stones }> \\
2 \mathrm{~mm}\end{array}$ \\
\hline
\end{tabular}

\section{Conclusion}

Although evidence for bilateral simultaneous endourological procedures is limited, results from available studies show that outcomes are at least equivalent to staged procedures. Key advantages seem to be reduced operative times, cost and hospital stay which will lead to an increased uptake of these procedures in the future.

Contributors to the Manuscript Robert Geraghty-Data collection, manuscript writing and data analysis

Patrick Jones - Data analysis and editing

Bhaskar K Somani-Project development, protocol and editing
Table 7 Complications of bilateral simultaneous procedures

\begin{tabular}{|c|c|c|c|}
\hline Complications & BS-PCNL, $n$ & BS-URS, n & $\mathrm{URS}+\mathrm{PCNL}, n$ \\
\hline Clavien I-II & $(n=204)$ & $(n=224)$ & $(n=6)$ \\
\hline Fever & 23 & 34 & 4 \\
\hline Haematuria & 2 & 52 & 0 \\
\hline Bleeding & 2 & 0 & 1 \\
\hline $\begin{array}{l}\text { Post-operative renal } \\
\text { insufficiency }\end{array}$ & 0 & 0 & 1 \\
\hline Required transfusion & 31 & 0 & 0 \\
\hline Infection & 11 & 11 & 0 \\
\hline Pain & 3 & 53 & 0 \\
\hline Stent symptoms & 0 & 2 & 0 \\
\hline Renal fistula & 10 & 0 & 0 \\
\hline Urinoma & 0 & 1 & 0 \\
\hline Mucosal injury & 0 & 40 & 0 \\
\hline Stone migration & 0 & 5 & 0 \\
\hline Urge incontinence & 0 & 1 & 0 \\
\hline Retention & 0 & 2 & 0 \\
\hline NOS & 122 & 23 & 0 \\
\hline Clavien $\geq$ III & $(n=46)$ & $(n=19)$ & $(n=0)$ \\
\hline AKI & 1 & 1 & 0 \\
\hline Hydrothorax & 11 & 0 & 0 \\
\hline Hydronephrosis & 0 & 2 & 0 \\
\hline $\begin{array}{l}\text { Required stenting } \\
\text { for drainage }\end{array}$ & 6 & 0 & 0 \\
\hline Urine leak & 7 & 0 & 0 \\
\hline Perforation & 1 & 11 & 0 \\
\hline Sepsis & 1 & 3 & 0 \\
\hline Death & 0 & 2 & 0 \\
\hline NOS & 19 & 0 & 0 \\
\hline Total $(n, \%)$ & $250(40 \%)$ & $243(26 \%)$ & $6(4 \%)$ \\
\hline
\end{tabular}

\section{Compliance with Ethical Standards}

Conflict of Interest Robert M. Geraghty and Patrick Jones each declare that there is no conflict of interest. Bhaskar K. Somani is a section editor for Current Urology Reports.

Human and Animal Rights and Informed Consent All procedures performed in studies involving human participants were in accordance with the ethical standards of the institutional and/or national research committee and with the 1964 Helsinki declaration and its later amendments or comparable ethical standards.

Open Access This article is distributed under the terms of the Creative Commons Attribution 4.0 International License (http:// creativecommons.org/licenses/by/4.0/), which permits unrestricted use, distribution, and reproduction in any medium, provided you give appropriate credit to the original author(s) and the source, provide a link to the Creative Commons license, and indicate if changes were made.

Publisher's Note Springer Nature remains neutral with regard to jurisdictional claims in published maps and institutional affiliations. 


\section{References}

Papers of particular interest, published recently, have been highlighted as:

-• Of major importance

1.• Scales CD Jr, Smith AC, Hanley JM, et al. Prevalence of kidney stones in the United States. European Urology. 2012;62:160-5 A large cross-sectional study detailing prevalence of stone disease amongst North Americans.

2. Türk C, Knoll T, Petrik A, et al. EAU guidelines on urolithiasis. 2016. (Accessed 03-08-2018).

3. Geraghty RM, Jones P, Somani BK. Worldwide trends of urinary stone disease treatment over the last two decades: a systematic review. J Endourol. 2017;31:547-56.

4. Ahlstrand C, Tiselius HG. Renal stone disease in a Swedish District during one year. Scand J Urol Nephrol. 2010;15:143-6.

5. Higgins JP, Green S, editors. Cochrane handbook for systematic reviews of interventions. Chichester: John Wiley \& Sons, Ltd; 2008. accessed 03/08/2018

6. Schünemann H, Brożek J, Guyatt G, et al. GRADE handbook for grading quality of evidence and strength of recommendations. guidelinedevelopment.orghandbook. 2013. (Accessed 03/08/2018).

7. Geraghty RM, Rai BP, Jones P, et al. Bilateral simultaneous ureteroscopic (BS-URS) approach in the management of bilateral urolithiasis is a safe and effective strategy in the contemporary era- evidence from a systematic review. 2017. 1-9.

8. Ingimarsson JP, Rivera M, Knoedler JJ, Krambeck AE. Same-session bilateral ureteroscopy: safety and outcomes. Urology. 2017;108:29-33.

9. Pace KT, Kroczak T, Wijnstok NJ, Kamphuis GM, Esen T, Toutziaris C, et al. Same session bilateral ureteroscopy for multiple stones: results from the CROES URS global study. J Urol. 2017;198:130-7.

10. Zveren BÃ, Eren MT, Özveri H, et al. Bilateral same-session ureterorenoscopy: a feasible approach to treat pan-urinary stone disease. Journal of Urology. 2017. 1-7.

11. Yang B, Ning H, Liu Z, Zhang Y, Yu C, Zhang X, et al. Safety and efficacy of flexible ureteroscopy in combination with holmium laser lithotripsy for the treatment of bilateral upper urinary tract calculi. Urol Int. 2017;98:418-24.

12. Jones P, Dhliwayo B, Rai BP, Mokete M, Amitharaj R, Aboumarzouk $\mathrm{OM}$, et al. Safety, feasibility, and efficacy of bilateral synchronous percutaneous nephrolithotomy for bilateral stone disease: evidence from a systematic review. J Endourol. 2017;31:334 40.

13. Liang $\mathrm{T}$, Zhao $\mathrm{C}, \mathrm{Wu} \mathrm{G}$, et al 2017. Multi-tract percutaneous nephrolithotomy combined with EMS lithotripsy for bilateral complex renal stones: our experience: $1-5$.
14. Rivera ME, Bhojani N, Heinsimer K, el Tayeb MM, Paonessa JE, Krambeck AE, et al. A survey regarding preference in the management of bilateral stone disease and a comparison of Clavien complication rates in bilateral vs unilateral percutaneous nephrolithotomy. Urology. 2018;111:48-53.

15. Wirtz P, Krambeck AE, Handa SE, Terry C, Lingeman JE. Contralateral Ureteroscopy performed at percutaneous nephrolithotomy: a unique evaluation of stone-free rates. J Urol. 2010;184:2378-82.

16. Shen PF, Liu N, Wei WR, Xu P, Li S, Luo YH, et al. Simultaneous ureteroscopic lithotripsy and contralateral percutaneous nephrolithotomy for ureteral calculi combined with renal staghorn calculi. Int J Urol. 2015;22:943-8.

17. Kwon O, Park J, Cho MC, Son H, Jeong H, Cho SY. Feasibility of single-session endoscopic combined intrarenal surgery for ipsilateral large renal stones and retrograde intrarenal surgery for contralateral renal stones: initial experience. Int J Urol. 2017;24:377-82.

18. Wang CJ, Chang CH, Huang SW. Simultaneous bilateral tubeless percutaneous nephrolithotomy of staghorn stones: a prospective randomized controlled study. Urol Res. 2010;39:289-94.

19. Kadlec AO, Greco KA, Fridirici ZC, Hart ST, Vellos TG, Turk TM. Comparison of complication rates for unilateral and bilateral percutaneous nephrolithotomy (PCNL) using a modified Clavien grading system. BJUI. 2013;111(4 Pt B):E243-8.

20. Coward RJM, Peters CJ, Duffy PG, Corry D, Kellett MJ, Choong S, et al. Epidemiology of paediatric renal stone disease in the UK. Arch Dis Child. 2003;88:962-5.

21. Hollenbeck BK, Schuster TG, Faerber GJ, Wolf JS Jr. Safety and efficacy of same-session bilateral ureteroscopy. J Endourol. 2003;17: $881-5$.

22. Ghosh A, Oliver R, Way C, et al. Results of day-case ureterorenoscopy (DC-URS) for stone disease: prospective outcomes over 4.5 years. World Journal of Urology. 2017;35(11):1757-64.

23. Somani BK, Desai M, Traxer O, Lahme S. Stone free rate (SFR): a new proposal for defining levels of SFR. Urolithiasis. 2014;42(2):95.

24. Wright A, Rukin N, Smith D, de la Rosette J, Somani BK. 'Mini, ultra, micro' - nomenclature and cost of these new minimally invasive percutaneous nephrolithotomy (PCNL) techniques. Ther Adv Urol. 2016;8(2):142-6.

25. Wong Y, Cook P, Roderick P, Somani BK. Metabolic syndrome and kidney stone disease: a systematic review of literature. J Endourol. 2016;30(3):246-53.

26. Ishii H, Griffin S, Somani BK. Ureteroscopy for stone disease in the paediatric population - a systematic review. BJUI. 2015;115(6):86773.

27. Ishii H, Abouramzouk O, Somani BK. Current status of ureteroscopy for stone disease in pregnancy. Urolithiasis. 2014;42(1):1-7. 